\title{
Fiscalidad e independencia en Panamá, 1780-1845
}

\section{Taxation and independence in Panama 1780 - 1845}

\author{
José Joaquín Pinto Bernal \\ Profesor Facultad de Ciencias Humanas y Artes Universidad del Tolima \\ jipintob@ut.edu.co \\ Fecha de recepción 6 de febrero de 2014 \\ Fecha de aprobación 25 de abril de 2014
}

\section{Resumen}

El artículo analiza la historia fiscal de Panamá entre 1780 y 1845 a través del estudio de las leyes y series fiscales, interpretadas con base en la situación política y económica de la época. El trabajo está dividido en cuatro secciones: la primera abarca la aplicación de las reformas borbónicas en Panamá; la segunda se ocupa del estudio del fisco durante la crisis del Estado colonial en América; la tercera abarca el período de existencia de la Gran Colombia, y la última concierne a la conformación de la República de la Nueva Granada, hasta 1845. En cada uno de los apartados se hace énfasis en el conflicto presentado entre la élite comercial de Panamá, las autoridades españolas y las bogotanas como producto de la necesidad del comercio libre para la prosperidad económica y estabilidad política en el Istmo.

Palabras clave: Historia económica, fiscalidad, gobierno, América Latina.

Códigos JEL: N00, H71, N4, N46 


\begin{abstract}
The article analyzes the fiscal history of Panama between 1780 and 1845 through the study of the tax laws and tax series, performed based on the political and economic situation of the time. The work is divided into four sections: the first covers the application of the Bourbon reforms in Panama, the second deals with the study of the taxation during the crisis of the colonial state in America, the third covers the period of existence of the Gran Colombia and latter concerns the formation of the Republic of New Granada until 1845. In Each section discusses the conflict presented between commercial elite from Panama and the authorities from Spain and Bogotá as a result of the need for free trade for economic prosperity and political stability in the Isthmus.
\end{abstract}

Keywords: Taxation, independence, Panama economic history.

JEL Codes: N00, H71, N4, N46 


\section{Introducción}

El estudio de la historia fiscal ha tenido un amplio desarrollo desde la publicación en 1918 del artículo escrito por Joseph Schumpeter (2000) titulado "La crisis del Estado fiscal", trabajo en el cual el autor resaltó la importancia del estudio de esta área a la hora de comprender el desarrollo de las actividades económicas y las estructuras políticas en diversas épocas. En este escrito, Schumpeter demostró cómo el análisis de la evolución de la estructura fiscal debe hacerse desde una doble concepción, entendiendo al fisco como efecto del orden político y económico de las sociedades, pero también enfatiza en la necesidad de comprender el sistema fiscal como ente determinante de la consolidación del ejercicio del poder y del desarrollo económico (Schumpeter, 2000, p. 150).

Los preceptos teóricos y metodológicos expuestos por Schumpeter tuvieron una gran influencia en investigadores que iniciaron todo un programa de estudio del fisco como elemento fundamental para la comprensión de la formación del Estado moderno y de las economías de mercado. Un claro ejemplo de estos trabajos fue el desarrollado por John Brewer (1989), quien llegó a la formulación del concepto "Estado fiscal militar" para explicar el aumento del poder político y económico de Inglaterra desde finales del siglo XVII. Según Brewer, el Estado se ocupó, en una primera instancia, en la consolidación del monopolio de la violencia interna como mecanismo de coacción para incrementar el recaudo, logrando fortalecer la armada e institucionalizar la deuda, respaldada con un alto margen de ingresos estatales (Brewer, 1989, p. 66); perspectiva que reñía con la esgrimida por Dickson (1976), para quien el fundamento del incremento del poder inglés estuvo marcado por la centralización y organización de la deuda pública; al igual que se distanciaba del concepto de "Estado fiscal naval comercial" propuesto por O'Brien (1967), para quien el énfasis en la consolidación del aparato burocrático y fiscal tenía como fin el fortalecimiento de la Armada, más que del Ejército terrestre.

Sin embargo, el concepto "Estado fiscal militar" mostró una limitante en cuanto a su aplicación, ya que solo se refería al largo siglo XVIII (1689-1815), razón suficiente para que Richard Bonney (2004) propusiese el estudio de la historia fiscal a través del concepto de "Estado fiscal", en la medida en que el mismo hace referencia al proceso de formación de los Estados occidentales modernos como respuesta a los retos de las guerras hemisféricas, que obligaron a una constante reorganización de la estructura del fisco para hacer frente al creciente gasto bélico, proceso que se desarrollará desde el siglo XVI hasta el inicio de la Primera Guerra Mundial.

Los preceptos teóricos y metodológicos de estas vertientes han sido sintetizados por Gabriel Ardant (1975), quien propone un modelo completo para el desarrollo de la historia fiscal. En una primera instancia, Ardant plantea el estudio sistemático de la política fiscal como producto de los objetivos de los gobiernos y de los intereses de los grupos que los encabezan. Sin embargo, la historia del fisco no solo se ocupa del análisis de la ley, sino que debe ser capaz de evaluar el impacto de ella a través de la elaboración total de series estadísticas, desarrollando una sólida historia serial. Elaboradas estas dos tareas, es necesario estudiar los impactos de tales resultados en el orden económico, político y social; ya que los mismos dan pie a la reformulación de la política y la reorientación de los objetivos de gobierno, dando inicio de nuevo al ciclo de formulación de la política fiscal (Ardant, 1975, 164). Este complejo esquema fue aplicado por Ardant (1971) en su ya conocida historia del fisco francés y sirve de guía para el presente artículo. 
Estas vertientes de estudio han tenido un amplio desarrollo con base en la temprana construcción de la historia serial fiscal desde el siglo XIX, como lo demuestran los trabajos de Pablo Pebrer (1833), Stephen Dawell (1888) y William Kennedy (1913) para el caso inglés o los de Jean Clamageran (1866), Adolphe Vuitry (1866) y René Stourm (1885) en Francia. Contrario a ello, la historia serial del fisco en América Latina ha sido de temprana emergencia, pues solo hasta la segunda mitad del siglo XX se tuvieron noticias de series completas del fisco colonial en Perú (TePaske, Klein y Browm, 1982a), Alto Perú (TePaske, Klein y Browm, 1982b), el Cono Sur (TePaske, Klein y Browm, 1982c), Ecuador (Jara y TePaske, 1990), Nueva España (TePaske, Hernández y Hernández, 1976), y más recientemente, en la Nueva Granada (Meisel, 2011). Con base en estas series se ha producido una amplia bibliografía de análisis global del fisco colonial, destacándose los trabajos de Jara (1994), Klein (1994) y Marichal (1999), y otros que analizan factores específicos del mismo, como en una reciente compilación donde se aborda el tema de los situados (Marichal y Grafenstein, 2012).

A pesar del avance en términos de historia fiscal colonial, son escasos los trabajos que presentan una panorámica global del desarrollo del fisco entre el período tardo colonial y el temprano republicano, haciendo las salvedades del trabajo de Halperin (2005) y los trabajos contenidos en las ediciones conjuntas de Michael Bordo y Roberto Cortes-Conde (2006), Luis Jáuregui y José Antonio Serrano (1998), Ernest Sánchez Santiró, Luis Jáuregui y Antonio Ibarra (2001), trabajos que, a excepción del de Halperin, no presentan series completas para el análisis de cada uno de los escenarios tratados.

Para el caso panameño, se cuenta con los trabajos elaborados por Álvaro Jara (1994), quien establece, a través de series parciales, la importancia del Istmo en la defensa del Imperio español en América. También se encuentra el trabajo de Castillero Calvo (2004), donde se elabora un marco general de la fiscalidad colonial. Más recientemente, Flores Guzmán (2012) hizo un completo análisis de los situados limeños al Istmo; por su parte, el trabajo desarrollado por Pinto (2011) publica las series de ingreso y egreso durante el período gran colombiano, y el elaborado por Kalmanovitz (2012) estudia el fisco panameño entre 1850 y 1886.

Así, el presente artículo ilustra el desarrollo del fisco panameño entre 1780 y 1845 a través del estudio de la política fiscal y el análisis de las series completas de ingreso y egreso de la tesorería de la ciudad de Panamá, a la luz de la situación política y del desarrollo de las actividades productivas, aplicando la propuesta desarrollada por Ardant (1975). El primer apartado estará enfocado en el periodo 1780-1810, durante el cual entran en vigencia las reformas borbónicas e inicia el proceso de independencia en el Virreinato de la Nueva Granada, a cuya jurisdicción pertenecía el Istmo. Posterior a ello, se estudiará el devenir del fisco entre 18101821, año en el cual el Istmo logra su independencia de España. El tercer período abarcará entre 1821-1830, durante la vigencia de la Gran Colombia, cuando el Istmo tenía la categoría de departamento. El último apartado está dedicado al período comprendido entre 1830-1845, en el cual Panamá pasará a ser provincia de la República de la Nueva Granada, culminando con el inicio del proceso de negociación para la construcción del ferrocarril, que cambiará la dinámica económica de tierra firme. 


\section{Fiscalidad en las postrimerías del régimen colonial, 1780-1810}

El Estado metropolitano español, desde el advenimiento de los borbones al trono, tuvo como objetivo primordial centralizar y organizar el Gobierno, como lo muestra la política de Felipe V, quien buscó, a través de los decretos de nueva planta, centralizar las finanzas, eliminar las diferencias ocasionadas por las particularidades provinciales y lograr estabilidad monetaria (Comín Comín y Yun-Casalilla, 2012, p. 249), institucionalizando la Secretaría del Despacho Universal como máxima instancia del Ejecutivo (Dieu, 2009, p. 114). Sin embargo, gran parte de estos objetivos interiores no fueron realidades, debido a la composición heterogénea de la Hacienda metropolitana, que dejó a la Corona sin una fuente fundamental de fondos para sus empresas.

Las limitantes del fisco metropolitano generaron la imposibilidad de construir un Ejército y Armada fuertes, para hacer frente a los constantes retos que presentaban a la Corona hispana sus contrapartes europeas, materializados en varios conflictos armados, hecho que produjo la conformación de un Estado Fiscal Militar subdesarrollado (Torres Sánchez, 2008, p. 435). Tal y como lo demostró González Enciso (2008, pp. 294-295), existe una diferencia fundamental entre el modo de financiamiento del esfuerzo bélico en Inglaterra y España: mientras que los anglosajones sustentaban su empresa en el crédito otorgado por el sector mercantil, el cual, a través de la guerra, ampliaba sus mercados y acumulaba mayores ganancias que podían ser reinvertidas en una economía que brindaba respeto a la propiedad privada, en España, la guerra era financiada por prestamistas que buscaban asegurarse puestos dentro de la administración metropolitana, dificultando las reformas administrativas necesarias para consolidar el Estado Fiscal Militar.

Mientras que en Inglaterra la guerra fue el motor de consolidación del Estado a través de la construcción de una sólida burocracia y un Ejército profesional, en España se convirtió en una fuente de endeudamiento que, a la postre, terminaba con el empeño de las rentas y de los cargos burocráticos, lo cual llevó a los monarcas hispanos a tomar una actitud netamente defensiva, con un gasto 35\% más bajo que el de Inglaterra, evitando el déficit y buscando un presupuesto equilibrado (Torres Sánchez, 2008, p. 429). A pesar de ello, cabe recordar que, a diferencia de sus contrapartes, España contaba con la mayor fuente de recursos coloniales, pues América sería otro de sus campos de acción y una de sus mejores oportunidades para consolidar el Estado Fiscal Militar.

José del Campillo y Cosio sería el encargado del diseño de la política en América teniendo como objetivo primordial beneficiar la economía metropolitana, aumentando las remesas de Indias y generando una relación desigual comercial constante con las colonias. El logro del programa de reforma debía estar sustentado en el fortalecimiento del sistema defensivo de Indias y el mayor rendimiento de sus rentas a través de una vigilancia más estricta del funcionamiento del fisco. Así, la Corona implementó la política de comercio unificada para las Américas en 1778 y promulgó el establecimiento de los estancos de los bienes más lucrativos. Un sistema de defensa fuerte, una administración centralizada y el aumento de la presión fiscal fueron los componentes de la fórmula empleada en América.

Al mismo tiempo que las reformas borbónicas eran aplicadas en el Istmo, este sufría una aguda crisis económica. Como es bien sabido, la principal actividad económica de Panamá por 
aquel entonces era el comercio, siendo la puerta de entrada de las mercaderías que se dirigían al Pacífico sur, situación que cambió a partir de la apertura de la ruta del Cabo de Hornos. La nueva ruta significó que la actividad comercial decayera, lo cual tuvo un alto impacto, que fue solventado durante algún tiempo gracias a los situados limeños, el comercio de esclavos con la empresa de asiento Genovés Grillo y Lomelin, el contrabando y la venida de productos de La Habana para su intercambio por cacao guayaquileño y tejidos de vicuña cuencanos (Castillero Calvo, 2004, p. 457).

Dichos paliativos tuvieron un efecto de corta duración, debido a la delicada situación social y al declive del comercio como producto de las guerras de España con otras potencias. En efecto, Panamá había sufrido la constante presión inglesa a través del apoyo que dicha nación aportó a la sublevación de varios pueblos nativos, lo cual llevaría a la expulsión de los españoles de San Blas y Darién en 1779 (Castillero Calvo, 2004, p. 507). La respuesta no se hizo esperar, y de inmediato el virrey de Nueva Granada Antonio Caballero y Góngora ordenó dos expediciones, en 1783 y 1785, llegando a su fin con el rendimiento de los indios cunas en 1787 (Castillero Calvo, 2004, p. 508), victoria que no se consolidó con la erección de fortalezas, debido a los recortes presupuestales aplicados por el virrey Ezpeleta, quien, como si fuera poco, suspendió el situado de Lima al Istmo (Ezpeleta, 1989, p. 279), el cual pudo ser restablecido poco tiempo después por el virrey Mendinueta (Mendinueta, 1989, p. 131).

A la par de ello, las transacciones del comercio exterior panameño iban en franco descenso, debido a los enfrentamientos de España con sus competidoras: Inglaterra (1779-1783, 17961802 y 1805-1807) y Francia (1793-1795). Las cifras de importación muestran una pendiente de regresión lineal de -21.112 entre 1771 y 1793, mientras que las exportaciones registran una pendiente de -17.659 (Castillero Calvo, 2004, 61). Como si ello fuera poco, las medidas encaminadas al establecimiento del estanco del tabaco y el aguardiente no habían tenido ningún efecto, pues ambas rentas se encontraban en el mayor desorden, como lo denunció el virrey Gil y Lemus en su relación de mando de 1789 (Gil y Lemus, 1989, p. 10).

Por ello, no es de extrañar que el Cabildo exigiese a la Corona en 1787 la total liberación del comercio de esclavos, dinero para la construcción de caminos, la fundación de nuevas poblaciones destinando los fondos de las medias anatas y lanzas para tal fin, la emisión de \$100.000 en monedas de buena ley para su uso exclusivo y el permiso para comerciar con colonias extranjeras y neutrales (Araúz y Pizzurno, 1991, pp. 254-255). La respuesta del Consejo de Indias llegaría en 1794, permitiendo el comercio de esclavos y negando los demás pedidos (Araúz y Pizzurno, 1991, p. 255). A cambio de ello, la metrópoli flexibilizó la política fiscal unificando todos los derechos al comercio exterior en uno solo, suprimiendo la alcabala de efectos de la tierra, el impuesto de 1,5\% sobre el comercio llamado unión de las armas y eliminando el cobro de la sisa (Castillero Calvo, 2004, p. 404). Aunque las medidas fueron bien recibidas, el gran anhelo de los comerciantes panameños tuvo que posponerse hasta 1797, cuando se les permitió el comercio con neutrales, debido a la guerra con Inglaterra, medida que sería suprimida en 1799 por el virrey Mendinueta de Santafé, para ser de nuevo concedida por el gobernador Mata, solo hasta 1808.

La difícil situación social, que acrecentaba el gasto militar; la caída de los situados como producto de la política virreinal; el descenso del comercio, ocasionado por las guerras de la metrópoli; la flexibilización de la política fiscal y la intermitente benevolencia comercial tu- 
vieron un fuerte impacto en la dinámica de ingreso y egreso de la caja de la ciudad de Panamá entre 1800-1809. Para analizar la dinámica del fisco hemos decidido tomar como referente las pendientes de regresión lineal interdecenales de los globales y de cada uno de los ramos. En la tabla 1 presentamos las cifras de ingreso entre 1780-1809, agrupadas con arreglo al método empleado por Klein (1973).

Tabla 1.

Ingresos de la Caja Real de Panamá, 1780-1809

\begin{tabular}{|c|c|c|c|c|c|c|c|c|c|c|c|}
\hline & Monopolios & Comercio & Iglesia & Minería & Empleados & Novenos & Tributos & Crédito & Varios & Otras cajas & \\
\hline 1780 & 88.995 & 16.044 & 1.946 & 8.188 & 3.608 & 700 & 1.337 & 0 & 3.609 & 605.939 & 730.366 \\
\hline 1781 & 149.187 & 379.866 & 0 & 506 & 0 & 4.045 & 1.808 & 0 & 0 & 289.044 & 824.456 \\
\hline 1782 & 146.683 & 377.159 & 197 & 506 & 3.473 & 4.039 & 1.768 & 0 & 122 & 280.492 & 814.439 \\
\hline 1783 & 169.032 & 27.951 & 1.838 & 514 & 1.540 & 4.034 & 2.180 & 0 & 0 & 271.940 & 479.029 \\
\hline 1784 & 141.674 & 371.763 & 0 & 506 & 0 & 4.028 & 1.689 & 0 & 0 & 263.388 & 783.048 \\
\hline 1785 & 139.169 & 369.056 & 0 & 506 & 0 & 4.022 & 1.649 & 0 & 0 & 254.837 & 769.239 \\
\hline 1786 & 41.042 & 38.598 & 13.095 & 349 & 7.363 & 1.453 & 316 & 0 & 328.356 & 130.734 & 561.306 \\
\hline 1787 & 134.161 & 363.661 & 0 & 505 & 0 & 4.010 & 1.570 & 0 & 0 & 237.733 & 741.640 \\
\hline 1788 & 131.656 & 360.973 & 0 & 505 & 0 & 4.005 & 1.530 & 0 & 0 & 229.181 & 727.850 \\
\hline 1789 & 75.334 & 26.516 & 2.716 & 660 & 1.830 & 1.810 & 3.232 & 0 & 5.289 & 533.772 & 651.159 \\
\hline 1790 & 238.851 & 495.243 & 2.767 & 304 & 4.333 & 11.694 & 937 & 0 & 70 & 932.114 & 1.686 .313 \\
\hline 1791 & 19.864 & 336.777 & 993 & 0 & 0 & 0 & 0 & 1.411 & 45.164 & 0 & 404.209 \\
\hline 1792 & 14.847 & 24.325 & 28.277 & 2.974 & 4.954 & 0 & 3.136 & 649 & 65.075 & 669.761 & 813.998 \\
\hline 1793 & 5.403 & 17.482 & 6.581 & 636 & 1.290 & 0 & 1.032 & 215 & 1.082 & 258.606 & 292.327 \\
\hline 1794 & 4.339 & 16.357 & 34.716 & 959 & 7.084 & 0 & 75 & 4.310 & 2.903 & 377.573 & 448.316 \\
\hline 1795 & 13.807 & 79.272 & 26.462 & 2.252 & 10.629 & 2.239 & 1.687 & 11.513 & 2.034 & 185.167 & 335.062 \\
\hline 1796 & 33.020 & 25.115 & 35.977 & 2.238 & 11.479 & 2.064 & 1.804 & 7.133 & 8.475 & 324.113 & 451.418 \\
\hline 1797 & 43.850 & 34.514 & 53.318 & 829 & 9.978 & 1.476 & 236 & 24.731 & 2.551 & 270.818 & 442.301 \\
\hline 1798 & 14.032 & 26.590 & 25.746 & 979 & 7.367 & 1.341 & 2.696 & 12.000 & 2.844 & 383.601 & 477.196 \\
\hline 1799 & 104.108 & 331.252 & 0 & 504 & 0 & 3.941 & 1.093 & 0 & 0 & 135.112 & 576.010 \\
\hline 1800 & 105.402 & 54.364 & 22.890 & 2.182 & 11.082 & 1.861 & 1.120 & 12.109 & 6.561 & 279.957 & 497.528 \\
\hline 1801 & 71.489 & 13.116 & 22.591 & 3.536 & 8.299 & 1.472 & 1.456 & 14.777 & 4.855 & 482.325 & 623.916 \\
\hline 1802 & 105.721 & 69.848 & 42.687 & 2.786 & 7.292 & 1.781 & 1.413 & 16.096 & 5.421 & 372.267 & 625.312 \\
\hline 1803 & 177.132 & 32.126 & 28.186 & 4.339 & 6.927 & 1.800 & 1.015 & 16.321 & 5.716 & 347.687 & 621.249 \\
\hline 1804 & 260.927 & 19.397 & 26.095 & 3.443 & 7.257 & 2.475 & 1.451 & 16.330 & 7.173 & 159.167 & 503.715 \\
\hline 1805 & 182.195 & 21.581 & 23.678 & 1.928 & 7.249 & 2.393 & 1.217 & 16.330 & 6.238 & 475.914 & 738.723 \\
\hline 1806 & 86.580 & 312.357 & 0 & 504 & 0 & 3.901 & 815 & 0 & 0 & 75.249 & 479.406 \\
\hline 1807 & 75.161 & 14.007 & 967 & 791 & 1.983 & 4.741 & 1.421 & 14.300 & 1.293 & 298.803 & 413.467 \\
\hline 1808 & 15.490 & 21.866 & 9.598 & 9 & 3.655 & 2.240 & 434 & 40.871 & 13.460 & 258.945 & 366.568 \\
\hline \multirow[t]{2}{*}{1809} & 58.619 & 204.964 & 18.888 & 1.513 & 7.886 & 2.240 & 1.906 & 39.246 & 2.747 & 264.829 & 602.838 \\
\hline & 2.847 .770 & 4.482 .140 & 430.209 & 45.451 & 136.558 & 79.805 & 42.023 & 248.342 & 521.038 & 9.649 .068 & 18.482 .404 \\
\hline
\end{tabular}

Fuente: elaboración propia con base en

Archivo General de la Nación: Sección: Colonia. Fondo: Real Hacienda. Tomos: 36, 30 y 53.

Archivo General de la Nación: Sección: Archivo Anexo II. Fondo: Real Hacienda Cuentas. Caja: 23.

David M. Rubenstein, Rare Book \& Manuscript Library. Duke University. John Jay TePaske Papers, 1500s-1988.

Caja: 7. 
Durante el período 1780-1809, los ingresos globales de la caja real de Panamá tendían a la baja; entre 1780-1789, la pendiente de regresión lineal se ubica en -9.213, que se acentúa entre 17901800, debido a la culminación del breve período de paz entre la metrópoli y sus contrincantes, registrando una pendiente de -66.523 , situación que logra solventarse mediante las medidas de permiso para el comercio con neutrales y colonias extranjeras, así como el restablecimiento del situado limeño, registrándose una pendiente de 12.748 entre 1800 y 1809 . Como lo muestra el gráfico 1, los ingresos totales de la caja dependieron fundamentalmente de las remisiones limeñas.

Gráfico 1.

Ingresos totales y situados de la Caja Real de Panamá, 1780-1809

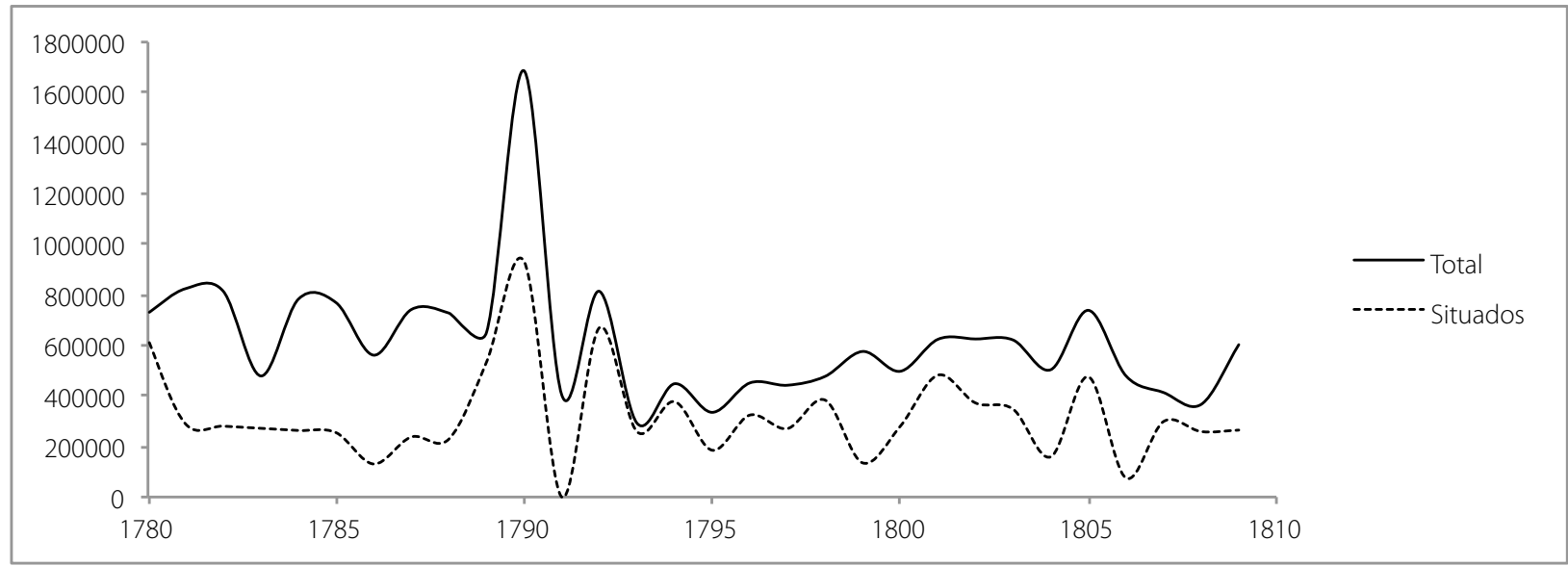

Fuente: elaboración propia con base en Archivo General de la Nación: Sección: Colonia. Fondo: Real Hacienda. Tomos: 36, 30 y 53.

Archivo General de la Nación: Sección: Archivo Anexo II. Fondo: Real Hacienda Cuentas. Caja: 23.

David M. Rubenstein, Rare Book \& Manuscript Library. Duke University. John Jay TePaske Papers, 1500 s-1988. Caja: 7.

La composición de los ingresos ilustra el predominio del situado, con una participación del $52 \%$, ramo que registra una constante caída entre 1780-1809, décadas en las cuales todas las pendientes de regresión lineal muestran resultados negativos. El segundo ramo en importancia en la composición del ingreso de la Caja está representado por los gravámenes al comercio, de $24,3 \%$, con una dinámica de rápido deterioro entre 1780-1799, décadas en las cuales el comercio se encontraba interrumpido por las guerras metropolitanas. La siguiente década registra una pendiente positiva de 12.002, gracias a la implementación de las políticas de comercio libre y la unificación de los gravámenes al comercio exterior. El siguiente rubro está representado por los monopolios, que aportaban el 15,4\% del total del ingreso, siendo el más representativo el del tabaco, seguido del aguardiente.

Los restantes rubros tienen una escasa participación dentro del global, como los ingresos varios, con el 2,8\%; los impuestos eclesiásticos, con el 2,3\%; el recurso al crédito, con el 1,3\%; los descuentos a empleados, con el 0,7\%; los novenos, con el 0,4\%; la minería y los tributos, con el $2 \%$ cada uno. Llama la atención la escasa participación de rubros como el tributo y los novenos, dando fe de la caracterización de la economía panameña, dominada por el sector de servicios (Castillero Calvo, 2004, p. 457). 
Como es evidente, el fisco panameño dependía de los situados y de los gravámenes comerciales, ramos que, juntos, aportaron el 76,5\% del total ingresado. Bien es sabido que casi la totalidad del situado limeño fue gastado en el Ejército (Flores Guzmán, 2012, p. 48) y que dicha tendencia se incrementó con el aumento del pie de fuerza en el Istmo durante la segunda mitad del siglo XVIII (Flores Guzmán, 2012, p. 49); por tanto, la disminución de los situados limeños, bien sea por las dificultades que el fisco andino sufría o por la política del Virreinato santafereño, producía una delicada situación de orden social al privar a la tropa de sus pagos, además de dejar a la plaza sin numerario. Dicha reducción se evidencia en la pendiente de la ecuación de regresión lineal del situado limeño con un valor de -4,753 entre 1780-1800 (Flores Guzmán, 2012, p. 59), y se agravaba si a ello se le suma el freno de las actividades comerciales por las guerras metropolitanas. De allí la explicación de por qué el Cabildo de la ciudad de Panamá pugnaba por permisos para el comercio libre y una reducción de las tasas arancelarias, lo cual tuvo una intermitente respuesta por parte de la Corona.

La situación crítica del fisco panameño se evidencia con una mayor dimensión si, además de tomar en cuenta la reducción de los situados, del comercio exterior y la política fiscal titubeante metropolitana, se le agrega el hecho de que todas las pendientes de regresión lineal del gasto global para las tres décadas estudiadas muestran una tendencia al alza, de 99,245 entre 1780-1789; de 58,767 entre 1790-1799, y de 16,024 entre 1800-1809. Dichos gastos en su mayor parte fueron destinados al sector armado, con el $71 \%$ del total, mientras que la administración civil solo consumió el $23 \%$, la Iglesia el $3 \%$ y las remisiones a cajas subalternas el 1\%. La necesidad de hacer frente a estas erogaciones obligó a hacer uso cada vez más a menudo del crédito, rubro que presentó pendientes de incremento de 1,348 para la década de los noventa y de 2,236 para la primera del siglo XIX. Las cifras nominales de gasto se presentan en la tabla 2.

Tabla 2.

Gastos de la Caja Real de Panamá, 1780-1809

\begin{tabular}{|c|c|c|c|c|c|c|}
\hline & Gastos militares & Gastos generales & Sueldos de burocracia & Gastos eclesiásticos & Otras cajas & \\
\hline 1780 & 176.937 & 0 & 0 & 0 & 0 & 176.937 \\
\hline 1786 & 21.559 & 86.523 & 342.494 & 7.264 & 0 & 457.840 \\
\hline 1789 & 141.434 & 147.564 & 19.192 & 11.822 & 55.414 & 375.426 \\
\hline 1792 & 204.442 & 104.312 & 17.524 & 15.180 & 418.182 & 759.640 \\
\hline 1793 & 135.333 & 23.590 & 12.805 & 8.294 & 55.000 & 235.022 \\
\hline 1794 & 334.898 & 60.287 & 24.918 & 29.148 & 38.868 & 488.119 \\
\hline 1795 & 337.148 & 68.405 & 23.829 & 18.320 & 60.314 & 508.016 \\
\hline 1796 & 296.542 & 146.784 & 15.428 & 9.519 & 84.184 & 552.457 \\
\hline 1797 & 385.227 & 81.571 & 16.607 & 25.156 & 0 & 508.561 \\
\hline 1798 & 948.073 & 56.474 & 18.370 & 8.236 & 73.177 & 1.104 .330 \\
\hline 1800 & 403.163 & 118.484 & 19.495 & 15.265 & 83.123 & 639.530 \\
\hline 1801 & 897.887 & 122.458 & 18.304 & 8.777 & 62.764 & 1.110 .190 \\
\hline 1802 & 314.740 & 97.786 & 17.564 & 27.912 & 78.984 & 536.986 \\
\hline 1803 & 224.361 & 62.105 & 22.899 & 69.618 & 31.074 & 410.057 \\
\hline
\end{tabular}




\begin{tabular}{|r|r|r|r|r|r|r|}
\hline $\mathbf{1 8 0 4}$ & 295.453 & 66.543 & 17.135 & 14.819 & 57.372 & $\mathbf{4 5 1 . 3 2 2}$ \\
\hline $\mathbf{1 8 0 5}$ & 364.235 & 224.297 & 14.201 & 6.350 & 44.937 & $\mathbf{6 5 4 . 0 2 0}$ \\
\hline $\mathbf{1 8 0 9}$ & 854.054 & 169.554 & 20.287 & 21.009 & 56.847 & $\mathbf{1 . 1 2 1 . 7 5 1}$ \\
\hline & $\mathbf{6 . 3 3 5 . 4 8 6}$ & $\mathbf{1 . 6 3 6 . 7 3 7}$ & $\mathbf{6 2 1 . 0 5 2}$ & $\mathbf{2 9 6 . 6 8 9}$ & $\mathbf{7 3 . 0 0 0}$ & $\mathbf{8 . 9 6 2 . 9 6 4}$ \\
\hline
\end{tabular}

Fuente: elaboración propia con base en Archivo General de la Nación: Sección: Colonia. Fondo: Real Hacienda. Tomos: 36, 30 y 53. Archivo General de la Nación: Sección: Archivo Anexo II. Fondo: Real Hacienda Cuentas. Caja: 23. David M. Rubenstein Rare Book \& Manuscript Library. Duke University. John Jay TePaske Papers, 1500s-1988. Caja: 7.

Así, el fisco panameño refleja una creciente crisis en los albores del siglo XIX, agravada por el aumento del gasto militar y por la reducción de los situados y de la actividad comercial. Ante este panorama, la élite comercial panameña representada en el Cabildo buscó la forma de exigir de un modo directo a la metrópoli, el permiso para el tráfico con colonias extranjeras y neutrales durante las guerras metropolitanas, a lo cual respondió la Corona con una tenue flexibilización de los aranceles y con el permiso para comerciar libremente de forma transitoria. Así, la tensión entre autoridades metropolitanas y élite comercial se hacía más fuerte, agravando la preocupante situación de orden social, manifiesta en las continuas pugnas con las comunidades indígenas y con una creciente plaza armada, tensión que tendría sorprendentemente un respiro durante la década de crisis política del orden colonial en América, período que se abordará en el siguiente apartado.

\section{Fiscalidad en la fiel Panamá, 1810-1821}

Conocido es que la usurpación del trono español por parte de José Bonaparte fue el detonante para la conformación de la resistencia en la metrópoli encabezada por la Junta Central de Gobierno, institución que reconoció representación a los americanos, medida que fue acogida con recelo por los criollos, debido a la desigualdad con la que fue otorgada respecto al número reducido de representantes con el cual contarían las colonias. La Junta se disolvió a comienzos de 1810 convocando a Cortes y dejando el poder ejecutivo al Consejo de Regencia, quien de inmediato envió a Carlos Montúfar a la Presidencia de Quito y a Antonio Villavicencio al Virreinato de la Nueva Granada como comisionados para calmar la tensa situación política, tensión que se manifestó en la erección de juntas autónomas de gobierno, rápidamente reprimidas en Quito y Charcas.

Montúfar y Villavicencio dieron el impulso final para la conformación de juntas (Martínez Garnica, 2000, p. 303) que reconociesen a la regencia y que mantuviesen el orden político tal como subsistió antes de 1809; sin embargo, las juntas no reconocieron a la regencia e iniciaron procesos de reforma en cada una de sus jurisdicciones. Dicha actitud provocó tensiones entre las provincias y los cabildos que se querían erigir en tales, entre provincias que se abrogaban el derecho de centralizar a las demás y entre autonomistas y gobiernos fieles a la regencia (Martínez Garnica, 1998, pp. 31-32). Así, Santa Marta, Riohacha, Guayaquil, Maracaibo, Coro, Guayana, Cuenca y Panamá tomaron partido por el bando realista en contra de los impulsos autonomistas de sus similares, convirtiendo al Istmo en sede del gobierno virreinal con la lle- 
gada de Benito Pérez en 1811, y en pieza clave para las operaciones desarrolladas por el virrey Montalvo en Santa Marta desde 1813, contra Cartagena y Caracas.

Durante la década del diez, Panamá experimentó un inusitado auge comercial, debido al desvío del comercio guayaquileño, mexicano y neogranadino hacia sus puertos; además de ello, gozó del anhelado permiso para comerciar con colonias extranjeras y neutrales entre 1808 y 1816, tomando un papel fundamental el comercio con Jamaica (Castillero Calvo, 2004, p. 3), situación que le permitió hacer frente a la constante crisis fiscal vivida entre 1780-1809, como bien lo explicó Salvador Bernabeu de Reguart:

Es constante que habiéndose visto estas cajas reales en los mayores apuros por falta de caudales desde principios de 1808 para mantener las guarniciones de esta plaza, Portovelo, y otros puertos avanzados, a causa de habernos suspendido los auxilios del situado que anualmente se contribuía de Cartagena, hubo de tratarse de buscar arbitrios para ocurrir a tan urgentes necesidades, por no ser bastantes los suplementos que se solicitaron del comercio. Celebróse al efecto junta de Real Hacienda a la que concurrí como ministro, y oídas las razones de extrema necesidad, que expuso como presidente de ella el gobernador de la plaza y el dictamen de dos letrados consultores (constantes en el expediente del asunto), se acordó a pluralidad de votos, el que se permitiese a este comercio el ir a Jamaica para traer en buques nacionales los frutos y efectos que tuviesen por conveniente, verificando su introducción por Chagre o Portovelo, que son los dos puertos menores de este istmo en el mar del norte, y satisfaciendo en $5 \%$ a la salida del dinero para colonias y $23 \%$ los efectos a su entrada. (Bernabeu de Reguart, 2008, p. 206)

La política de comercio libre fue mantenida con algunos sobresaltos hasta 1816, cuando fue suspendida, junto al cierre del puerto de Chagres, para evitar el contrabando (Araúz y Pizzurno, 1991, p. 263). Aunque el comercio libre y la erección del gobierno virreinal ayudaron a solventar la crisis fiscal, no significaron la eliminación de las tensiones existentes entre la política colonial y las intenciones de la élite comercial. En efecto, como lo demuestran el tratado escrito por Salvador Bernabeu de Reguart en 1809 (Bernabeu de Reguart, 2008, pp. 198-201) y las propuestas esgrimidas por Juan José Cabarcas y José Joaquín Ortiz como diputados del Istmo a las Cortes de Cádiz (Araúz y Pizzurno, 1991, p. 260), los criollos apuntaban a la eliminación de los estancos, el mantenimiento del comercio libre de forma permanente y la igualdad política ante la metrópoli; pedidos que no tuvieron nunca una respuesta afirmativa por parte de las autoridades realistas. Igualmente, los panameños exigieron una mayor independencia comercial frente al Consulado cartagenero, proponiendo en dos ocasiones, en 1812 y 1817, a través del Cabildo la erección de su propio consulado, medida que tampoco fue aprobada.

A la par de estas fuertes tensiones, Panamá tuvo que hacer frente a varios intentos de invasión por parte de las fuerzas independentistas, algunas sin ningún éxito, como la fallida expedición a Portobelo en 1815 (Montalvo, 1989, p. 203) y la efímera implementación de un gobierno republicano en la misma localidad en 1819, por parte de López Tagle y MacGregor (Martínez Delgado, 1972, p. 47) , las cuales exigieron una amplia movilización de recursos para la defensa del gobierno realista, que se vieron incrementados debido al envío de $\$ 80.000$ 
(Montalvo, 1989, p. 199) y un empréstito de $\$ 100.000$ (Montalvo, 1989, p. 205) hacia Santa Marta, con el fin de financiar las operaciones militares del virrey Montalvo.

Junto a las tensiones, para 1819 el Istmo experimentó el fin del auge comercial y la aparición del virrey Sámano en su jurisdicción, con el ánimo de aplicar el Régimen del Terror (Araúz y Pizzurno, 1991, p. 265). Los triunfos patriotas en Nueva Granada y la Audiencia de Quito fueron el epílogo de una década de efímero auge. En efecto, para 1819 el auge comercial había finalizado, producto de las guerras de independencia, que cerraban los circuitos de comercio, y para 1821 el gobernador Cruz Mourgeon reconocía un déficit fiscal de \$53.834 y el cierre total del comercio con Perú (Castllero Calvo, 2004, p. 13).

Como se dijo anteriormente, el auge del comercio panameño logró solventar la crisis fiscal presente desde 1780; prueba de ello es la pendiente de regresión lineal de ingreso entre 1810-1818, que registró 71.831, con incremento por primera vez en cuatro décadas. En efecto, el 52,3\% de los ingresos provinieron del comercio; sin embargo, los situados disminuyeron su participación llegando tan solo al 6,8\%, con pendiente de $-7,889$. El lugar de los situados fue ocupado por los ingresos eventuales, que llegaron a sumar el 23,5\%, con pendiente de 12,354; pero este alivio fue momentáneo, debido a que los rubros que componen el ramo son de carácter esporádico, siendo los más importantes los reintegros y las subvenciones extraordinarias para la guerra, que sumaron el $74 \%$ de todo el ramo. Por tanto, los gravámenes al comercio y las exacciones extraordinarias serían los dos principales determinantes del ingreso global, ocupando el lugar que dejarían los situados, interrumpidos como producto del desorden político en el Perú y la Nueva Granada, como se evidencia en el gráfico 2.

\section{Gráfico 2.}

Ingresos totales, de impuestos comerciales e ingresos eventuales de la Caja Real de Panamá, 1810-1818

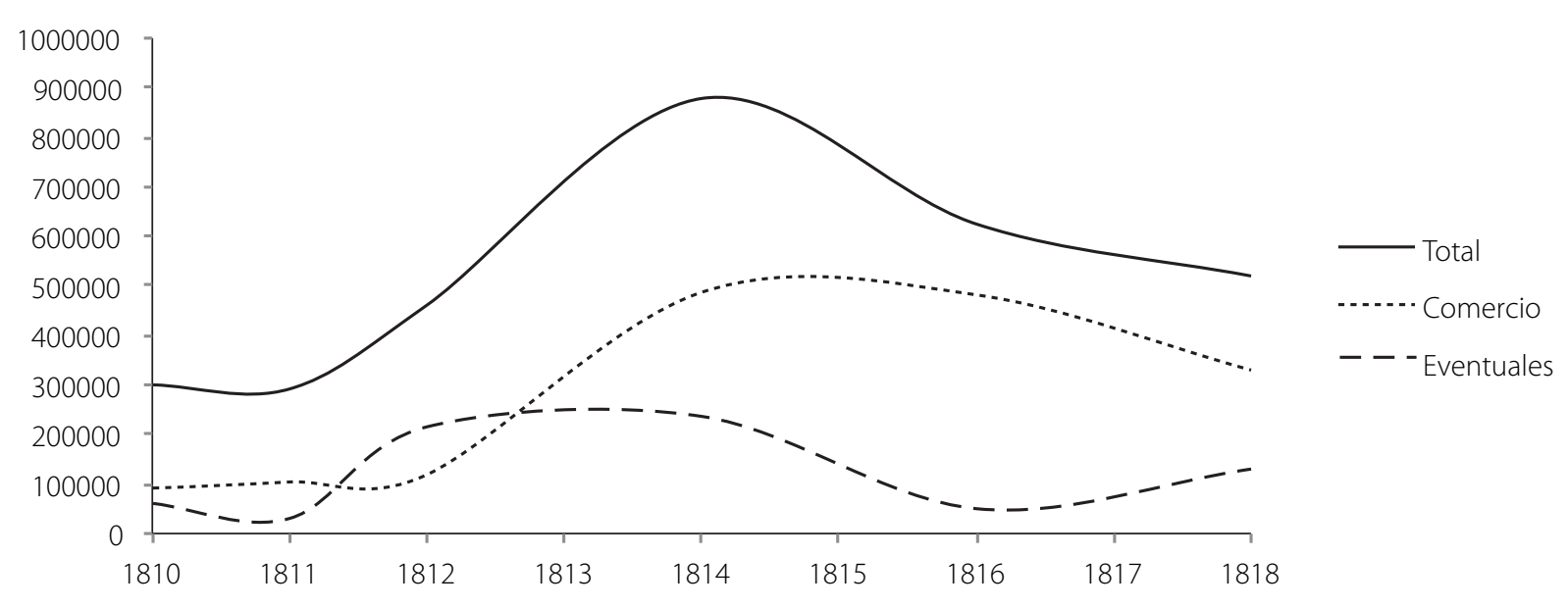

Fuente: elaboración propia con base en

Archivo General de la Nación: Sección: Colonia. Fondo: Real Hacienda. Tomo: 36, 30, 53.

Archivo General de la Nación: Sección: Archivo Anexo II. Fondo: Real Hacienda Cuentas. Caja: 23

Los ramos restantes tuvieron una participación menor en el total de la composición de los productos de la caja: los ingresos eclesiásticos aportaron el 5,9\% del total y los estancos 
el 4,7\% continuando su tendencia a la baja; el recurso al crédito también decayó, a pesar de las dificultades del final del período, y solo aportó el 4,6\%; el descuento a empleados sumó el 1,4\%; los novenos, el 0,5\%; los impuestos a la minería, el 0,2\%, y el tributo indígena, el 0,1\% (ver la tabla 3).

Tabla 3.

Ingresos de la Caja Real de Panamá 1810-1818

\begin{tabular}{|c|r|r|r|r|r|r|}
\hline & $\mathbf{1 8 1 0}$ & $\mathbf{1 8 1 1}$ & $\mathbf{1 8 1 2}$ & $\mathbf{1 8 1 4}$ & $\mathbf{1 8 1 6}$ & $\mathbf{1 8 1 8}$ \\
\hline Comercio & 89.395 & 103.790 & 118.639 & 486.755 & 481.475 & 329.618 \\
\hline Eventuales & 59.630 & 30.508 & 215.396 & 236.429 & 50.127 & 130.133 \\
\hline Otras tesorerías & 75.707 & 19.702 & 29.836 & 51.259 & 10.671 & 21.618 \\
\hline Eclesiásticos & 4.888 & 32.191 & 46.351 & 66.335 & 20.042 & 12.125 \\
\hline Estancos & 59.886 & 49.744 & 9.667 & 10.424 & 9.532 & 6.464 \\
\hline Crédito & 391 & 49.508 & 28.899 & 11.583 & 46.136 & 4.748 \\
\hline Empleados & 6.297 & 2.910 & 8.842 & 11.563 & 2.282 & 12.053 \\
\hline Novenos & 2.252 & 2.468 & 2.469 & 2.548 & 2.594 & 2.927 \\
\hline Minería & 306 & 778 & 779 & 1.346 & 1.818 & 156 \\
\hline Tributos & 1.356 & 300 & 300 & 0 & 0 & 0 \\
\hline & $\mathbf{3 0 0 . 1 0 8}$ & $\mathbf{2 9 1 . 8 9 9}$ & $\mathbf{4 6 1 . 1 7 8}$ & $\mathbf{8 7 8 . 2 4 2}$ & $\mathbf{6 2 4 . 6 7 7}$ & $\mathbf{5 1 9 . 8 4 2}$ \\
\hline
\end{tabular}

Fuente: elaboración propia con base en Archivo General de la Nación: Sección: Colonia. Fondo: Real Hacienda. Tomo: 36, 30, 53.

Archivo General de la Nación: Sección: Archivo Anexo II. Fondo: Real Hacienda Cuentas. Caja: 23

La composición del egreso en 1814-1818, de nuevo muestra la preeminencia del gasto militar, con el 56\% del total; las remisiones a otras cajas, entre las que se destacan Santa Marta y Maracaibo, ocupan el segundo lugar, con el 17,5\%; los gastos de gobierno consumieron el 16,3\%; la Iglesia, el 5,37\%, y el crédito, el 4,8\%, como lo demuestran las cifras de la tabla 4.

Tabla 4.

Gastos de la Caja Real de Panamá, 1810-1818

\begin{tabular}{|c|r|r|}
\hline & $\mathbf{1 8 1 4}$ & $\mathbf{1 8 1 8}$ \\
\hline Militares & 383.856 & $394.55 \mathrm{~W} 3$ \\
\hline Otras cajas & 236.992 & 4.838 \\
\hline Generales administración & 65.302 & 88.127 \\
\hline Eclesiásticos & 65.318 & 8.845 \\
\hline Sueldos burocracia & 50.934 & 21.281 \\
\hline Crédito & 61.946 & \\
\hline
\end{tabular}

Fuente: elaboración propia con base en Archivo General de la Nación: Sección: Archivo Anexo II. Fondo: Real Hacienda Cuentas. Caja: 23 
El momentáneo auge comercial significó la salida de la crisis fiscal, pero no fue suficiente para acallar las exigencias de la élite comercial, quien se sentía cada vez más incómoda en el régimen colonial, debido a las negativas a sus demandas. El final del ciclo de auge comercial y el mantenimiento de la tensión bélica en Portobelo y Nueva Granada significaron la necesidad de acudir al crédito y a los ingresos eventuales con subvenciones extraordinarias ante la desaparición de los situados cartageneros y limeños, lo cual acrecentó la incomodidad de los criollos, quienes se veían maniatados ante la negativa de llevar a cabo las reformas que proponían y frente a la posibilidad de implantación del Régimen del Terror tras la llegada de Sámano al Istmo; factores que aceleraron el desenlace independentista de 1821.

\section{Fiscalidad panameña en la República de Colombia, 1821-1830}

La situación política y económica se hacía más crítica a cada momento; Panamá se convirtió rápidamente en un lugar de alta concentración de tropas, lo que generaba constantes roces con la población; la falta de comercio dejaba a los naturales sin numerario y sin mercancías para consumo interno (Castillero Calvo, 2004, p. 22). Como si ello fuera poco, la élite comercial tenía que soportar la incómoda presencia de Sámano, quien, entre otros desaciertos, exigía contribuciones forzosas cada vez más para las Fuerzas Armadas, como en 1819, cuando elevó un empréstito de $\$ 53.834$ y persiguió a los miembros del Cabildo, quienes tuvieron que migrar a Jamaica y al interior (Araúz y Pizzurno, 1993, p. 25), hechos que promovían el levantamiento popular y la animadversión de la población hacia las fuerzas realistas, siendo incapaz de controlarlas el capitán Porras, quien le dejó la dura labor al nuevo gobernador, Cruz Mourgeon, tras la muerte de Sámano (Castillero Calvo, 2004, p. 25).

La gestión de Mourgeon logró apaciguar un poco los ánimos; sin embargo, la expresa orden de reconquistar la Audiencia de Quito desde el Istmo, le obligó a implantar de nuevo el sistema de contribuciones extraordinarias, exacerbando los ánimos de la élite comercial, que, tras la partida del capitán hacia las faldas del Pichincha, aprovechó la situación declarando la independencia en la Villa de los Santos, el 21 de noviembre de 1821, para, pocos días después, promover la formación del Cabildo Abierto en la ciudad de Panamá decretando la independencia del Istmo y su anexión a la República de Colombia, buscando la protección ante posibles invasiones desde Cuba y el regreso del capitán ausente (Castillero Calvo, 2004, p. 40). Así, Panamá pasaría a ser el departamento del Istmo de la recientemente conformada República de Colombia:

Mediante decreto ejecutivo de 9 de febrero de 1822, firmado por el vice-Presidente Santander, provisionalmente y hasta la próxima reunión del Congreso, se erigió el Departamento del Istmo, compuesto por los departamentos de la antigua Comandancia General de Panamá que permanecería con los mismos límites que antaño tenía con el gobierno español. El nuevo Departamento tendría los mismos derechos que los otros que formaban la República de Colombia. Se gobernaría por un magistrado bajo la denominación de Intendente con el sueldo y las demás facultades que las leyes asignaban a los demás de Colombia. Dicho funcionario residiría en la ciudad de Panamá, en tanto que los gobernadores de las otras Provincias del Istmo gozarían, mientras se resolviera otra cosa, de los sueldos que le estaban asignados por el gobierno español, 
aunque sujetos a los descuentos previstos en la legislación colombiana. (Araúz y Pizzurno, 1993, p. 26)

El cambio político en el Istmo poco significó para el mejoramiento de la economía a pesar del leve auge que experimentó su actividad mercantil durante el desarrollo de la campaña de independencia del sur. Después de 1824, la economía sufrió el deterioro de la actividad comercial, debido a la consolidación de la independencia continental, restableciéndose la funcionalidad del puerto de Veracruz y abriéndose de nuevo la ruta del Cabo de Hornos, plazas que representaban para los comerciantes reducción de costos, menores riesgos y una comunicación más expedita, a lo cual habría que sumar la escasa demanda de bienes de consumo de la región y la imposibilidad que la misma tenía para generar retornos en numerario ( Castillero Calvo, 2004, pp. 47-48).

Rápidamente, la élite comercial se dio cuenta de que la nueva situación política los dejaba de nuevo en el mismo punto que en 1810, exigiendo el comercio libre frente a un poder foráneo, ya no el de la metrópoli sino el de Bogotá, poder del cual se intentó prescindir a través de los proyectos solicitados a Inglaterra, con el ánimo de establecer franquicias comerciales independientes en 1826 y 1830, sin obtener respuesta por parte de los anglosajones (Castillero Calvo, 2004, p. 48). A la par de ello, iniciaba la crisis de la deuda americana, que desataría el pánico en la City en 1825, hecho que agravó la situación panameña. Sin embargo, la élite comercial intuyó que las causas de su ruina no se encontraban más allá del Atlántico sino en medio de la cordillera Oriental, debido al mantenimiento del pesado orden fiscal colonial por parte del Gobierno de Bogotá.

En efecto, una breve revisión de las reformas fiscales implantadas por el Gobierno de la República de Colombia revela el mantenimiento de aquel orden. En términos aduaneros, los aranceles se aumentaron en tres ocasiones, los impuestos eclesiásticos se mantuvieron iguales, el estanco del aguardiente se intentó abolir estableciendo el sistema de patentes en 1821, renaciendo solo cinco años después; el tabaco no tuvo mayores cambios, la alcabala se eliminó para bienes domésticos pero se aumentó al 2,5\% para bienes raíces y mercancías importadas, restableciéndose en 1828 para toda mercadería, con una tasa del 15\%; el tributo indígena se abolió en el Congreso de Cúcuta y fue restablecido en la dictadura de Bolívar, y la contribución directa fue un total fracaso (Pinto, 2011, pp. 57-73). Poco o nada había cambiado, y el Istmo se hundía en la crisis, ante lo cual la élite comercial protestaba de forma airada:

¿Pero quién querrá venir a nuestras playas y cultivar su suelo, para pagar derechos de exportación sobre sus producciones; otros de treinta y cinco por ciento sobre los efectos de importación, que lleguen a consumir un décimo de sus rentas en contribución directa al Estado, otro decimo de sus rentas en bruto a la iglesia, con varios otros que oprimen actualmente la agricultura del país, y todos los cuales juntos privan al labrador de la mitad de los frutos anuales de su trabajo? Aun cuando el país gemía bajo el estado de esclavitud del que ya está felizmente libre, no se había recurrido a los impuestos directos, y mucho menos a uno de esta naturaleza. La alcabala y algunos pocos manuales de rentas que ya hemos enumerado, con algunos suplementos ocasionales de México, eran entonces suficientes para mantener en la indolencia a los servidores públicos bien pensionados, capitanes generales de mucho 
lujo, y buena caterva de arpías que en la molicie y ociosidad engordaban con las partes vitales del país. (Gaceta del Istmo de Panamá, 1826, p. 2)

En medio de una aguda crisis económica y el cuestionamiento a la legitimidad de las órdenes del Gobierno central de la República de Colombia, en Panamá el fisco se encontraba moribundo. La pendiente de regresión lineal muestra una tendencia de ingreso global de -27.778, con una participación del $31 \%$ de los gravámenes comerciales, con tendencia a la baja. El recurso al crédito interno aportó el $25 \%$ del total mostrando tendencia al alza con una pendiente de 3,851, jalonando el ingreso total al final del periodo como producto del deterioro del ingreso por gravámenes comerciales. Las remisiones de otras tesorerías llegaron al $25 \%$ como producto de algunos envíos hechos por Cartagena y las tesorerías provinciales del Istmo, rubro con pendiente de -17,832 como resultado de su práctica desaparición después de 1825 . Las tendencias de cada ramo y el total son evidentes en el grafico 3.

\section{Gráfico 3.}

Ingresos totales, de impuestos comerciales, crédito y de remisiones de otras tesorerías en la tesorería general del Istmo, 1822-1830

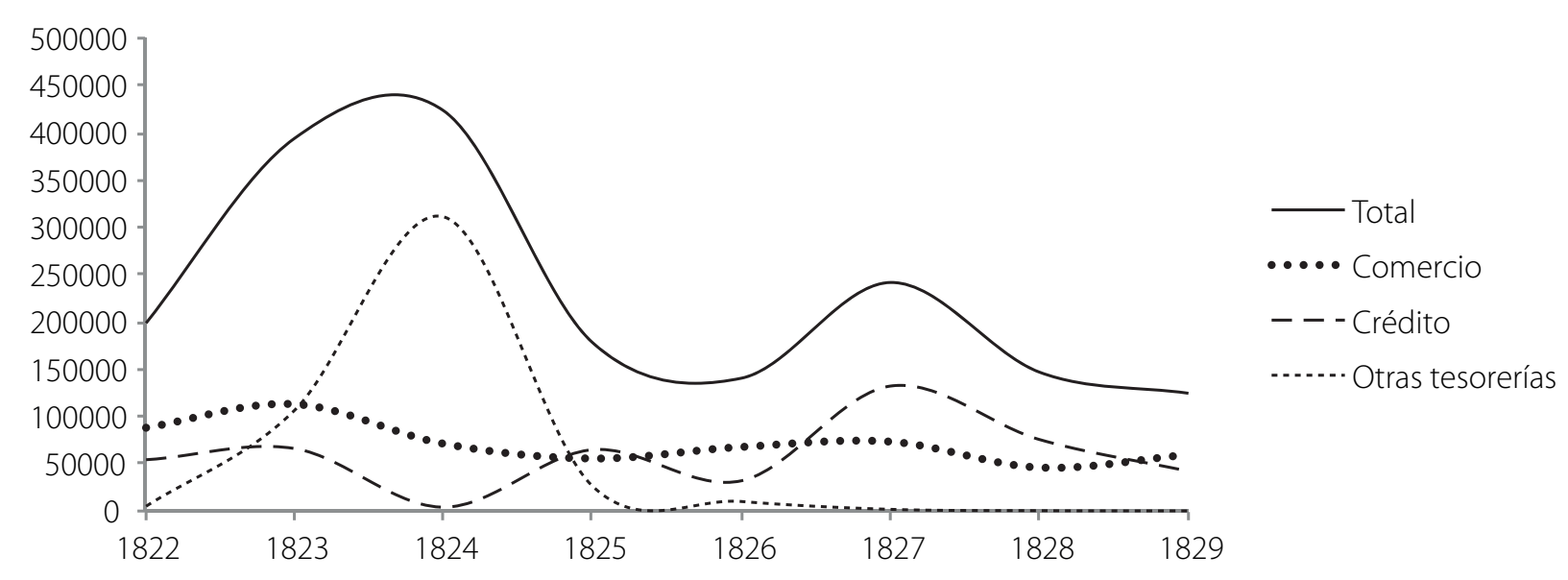

Fuente: elaboración propia con base en Archivo General de la Nación: Sección: República. Fondo: Ministerio de Hacienda. Tomos: 299 y 226. Gaceta de Colombia, n. 432 (1829)

Cucalón José, (1824-1825)

El resto de ramos poco aportaron: los estancos llegaron al 9\% del total con una fuerte tendencia a la baja, debido a la reformas en el ramo de aguardientes; los impuestos eclesiásticos llegaron al 6\%, los que gravaron la actividad agrícola aportaron el 2\%; y el tan anhelado progreso hacia la tributación directa solo llegó al 1\%, como lo muestran las cifras nominales de ingreso de la tabla 5. 
Tabla 5.

Ingresos de la tesorería general del Istmo, 1822-1830

\begin{tabular}{|c|r|r|r|r|r|r|r|r|r|}
\hline & $\mathbf{1 8 2 2 - 1 8 2 3}$ & $\mathbf{1 8 2 3 - 1 8 2 4}$ & $\mathbf{1 8 2 4 - 1 8 2 5}$ & $\mathbf{1 8 2 5}-\mathbf{1 8 2 6}$ & $\mathbf{1 8 2 6 - 1 8 2 7}$ & $\mathbf{1 8 2 7 - 1 8 2 8}$ & $\mathbf{1 8 2 8 - 1 8 2 9}$ & $\mathbf{1 8 2 9 - 1 8 3 0}$ & Totales \\
\hline Comercio & 88.454 & 113.029 & 71.252 & 55.562 & 67.773 & 73.343 & 46.016 & 59.538 & $\mathbf{5 7 4 . 9 6 7}$ \\
\hline Crédito & 52.857 & 66.151 & 4.098 & 64.825 & 32.000 & 132.140 & 75.622 & 42.123 & $\mathbf{4 6 9 . 8 1 6}$ \\
\hline Otras tesorerías & 3.639 & 106.187 & 311.154 & 26.531 & 10.090 & 1.811 & 390 & 152 & $\mathbf{4 5 9 . 9 5 4}$ \\
\hline Estancos & 23.164 & 60.682 & 19.590 & 20.219 & 16.255 & 17.474 & 7.533 & 7.304 & $\mathbf{1 7 2 . 2 2 1}$ \\
\hline Eclesíásticos & 17.825 & 35.446 & 8.751 & 6.523 & 8.502 & 11.751 & 10.502 & 9.456 & $\mathbf{1 0 8 . 7 5 6}$ \\
\hline Agricultura & 2.980 & 4.639 & 4.739 & 4.685 & 5.840 & 5.161 & 6.798 & 5.956 & $\mathbf{4 0 . 7 9 8}$ \\
\hline Contribución directa & 9.184 & 7.711 & 3.955 & 0 & 0 & 0 & 4 & 0 & $\mathbf{2 0 . 8 5 4}$ \\
\hline Totales & $\mathbf{1 9 8 . 1 0 3}$ & $\mathbf{3 9 3 . 8 4 5}$ & $\mathbf{4 2 3 . 5 3 9}$ & $\mathbf{1 7 8 . 3 4 5}$ & $\mathbf{1 4 0 . 4 6 0}$ & $\mathbf{2 4 1 . 6 8 0}$ & $\mathbf{1 4 6 . 8 6 5}$ & $\mathbf{1 2 4 . 5 2 9}$ & $\mathbf{1 . 8 4 7 . 3 6 6}$ \\
\hline
\end{tabular}

Fuente: elaboración propia con base en:

Archivo General de la Nación: Sección: República. Fondo: Ministerio de Hacienda. Tomos: 299 y 226.

Gaceta de Colombia, 432 (1829)

Cucalón José, (1824-1825)

La composición del egreso muestra de nuevo el predominio del gasto militar, con el 41\%; las erogaciones del gobierno civil sumaron el 39\%, y aparece con mucha mayor fuerza el gasto por servicio de deuda, que sumó el $20 \%$, ya que parte de los fondos de aduanas y estancos estaba destinada a la amortización y los interés del empréstito contratado por la República de Colombia en 1824 con la casa comercial Goldsmith, junto con los empréstitos locales y las deudas reconocidas por Colombia provenientes del período de dominio español. Las cifras nominales de egreso se presentan en la tabla 6.

Tabla 6.

Egresos de la tesorería general del Istmo, 1822-1830

\begin{tabular}{|c|r|r|r|r|r|r|r|r|r|}
\hline & $\mathbf{1 8 2 2 - 1 8 2 3}$ & $\mathbf{1 8 2 3 - 1 8 2 4}$ & $\mathbf{1 8 2 4 - 1 8 2 5}$ & $\mathbf{1 8 2 5 - 1 8 2 6}$ & $\mathbf{1 8 2 6 - 1 8 2 7}$ & $\mathbf{1 8 2 7 - 1 8 2 8}$ & $\mathbf{1 8 2 8 - 1 8 2 9}$ & $\mathbf{1 8 2 9 - 1 8 3 0}$ & Totales \\
\hline Gasto civil & 96.300 & 126.857 & 94.710 & 101.523 & 115.623 & 91.748 & 54.960 & 75.421 & $\mathbf{7 5 7 . 1 4 2}$ \\
\hline Gasto militar & 68.443 & 160.413 & 228.298 & 84.562 & 94.875 & 63.599 & 48.578 & 51.240 & $\mathbf{8 0 0 . 0 0 8}$ \\
\hline Servicio de deuda & 33.171 & 91.421 & 3.884 & 54.215 & 64.217 & 83.582 & 43.332 & 21.547 & $\mathbf{3 9 5 . 3 6 9}$ \\
\hline Totales & $\mathbf{1 9 7 . 9 1 4}$ & $\mathbf{3 7 8 . 6 9 1}$ & $\mathbf{3 2 6 . 8 9 2}$ & $\mathbf{2 4 0 . 3 0 0}$ & $\mathbf{2 7 4 . 7 1 5}$ & $\mathbf{2 3 8 . 9 2 9}$ & $\mathbf{1 4 6 . 8 7 0}$ & $\mathbf{1 4 8 . 2 0 8}$ & $\mathbf{1 . 9 5 2 . 5 1 9}$ \\
\hline
\end{tabular}

Fuente: elaboración propia con base en

Archivo General de la Nación: Sección: República. Fondo: Ministerio de Hacienda. Tomos: 299 y 226.

Gaceta de Colombia, Nº 432 (1829)

Cucalón (1824 y 1825) 
Estas cifras dejan claro que la ruptura de los lazos coloniales en el Istmo de Panamá poco significó para el mejoramiento de las condiciones económicas, las cuales eran altamente dependientes del mantenimiento de flujos de numerario representados en situados, y de una constante actividad comercial, ante lo cual la élite siguió demandando mayor flexibilidad fiscal y una política comercial más libre, ya no a la metrópoli sino al Gobierno de la República de Colombia. La respuesta desde Bogotá no pudo ser otra que unos leves cambios en la estructura impositiva, los cuales tuvieron una vigencia muy corta, debido a las dificultades que sufría el fisco nacional como producto del elevado gasto militar, civil, y del ahora poderoso rubro del servicio de la deuda. Por tanto, la crisis fiscal y el descontento político siguieron siendo la constante, planteándose la posibilidad de la emancipación de Colombia, república que despareció entre las pugnas locales, en 1830.

\section{Fiscalidad panameña en la República de la Nueva Granada, 1830-1845}

Para 1830, el desorden interno en la República de Colombia era absoluto, razón por la cual, en el mismo año, se declararon independientes Venezuela y Ecuador, oleaje que tuvo un fuerte impacto en el Istmo, pues tras el abandono del poder por parte de Simón Bolívar, Panamá se declaró independiente de Bogotá en septiembre, a la espera de la llegada del Libertador, y se reintegró de nuevo a la República el 10 de diciembre, debido a la toma del poder por parte de Urdaneta; tan solo siete días después murió Bolívar en Santa Marta. Como bien lo ha expuesto Martínez Delgado (1972), en Panamá, durante la década del treinta la presión política se materializó en dos vertientes que proponían la separación de Colombia, una comandada por Mariano Arosemena, quien proponía la unión con Ecuador, y la otra alentada por José de Obaldía, y que perseguía la independencia total, bajo la protección de Inglaterra o Francia (Martínez Delgado, 1972, p. 67).

Las dos vertientes antes expuestas eran el lógico producto no solo del desorden interno de la República de la Nueva Granada, sino de la falta de respuesta por parte del Gobierno de Bogotá en relación con los reclamos que elevaba a cada instante la élite comercial panameña, la cual obtuvo como único aliciente a su clamor la promulgación, en 1835, de la ley de liberación de derechos de introducción en los puertos de Portobelo y Panamá, medida que estaba condicionada a la construcción de un canal o un ferrocarril, y que, por tanto, entró en vigencia solo hasta 1855, con la terminación de la línea férrea Colón-Panamá (Castillero, Calvo, 2004, p. 49).

Las peticiones de comercio libre, además de tener una arraigada tradición, respondían a la precaria situación en la que vivió la actividad mercantil en el Istmo, agravada en 1839 con el inicio de la Guerra de los Supremos en la Nueva Granada y la constante exigencia de fondos para suplir las necesidades de Cartagena, factor que se cuenta como una de las principales causas para que el 18 de noviembre de 1840, de nuevo, Panamá se declarase independiente y reuniese una Asamblea Constituyente, en marzo de 1841:

En vísperas del movimiento separatista del 18 de noviembre de 1840, había hecho crisis la reiterada resistencia de las dos últimas administraciones del Istmo, la de Obarrio primero y luego la de Icaza, a la exigencia bogotana de transferir fondos de las escuálidas arcas panameñas a las de Cartagena, lo que amenazaba con dejar seca 
la Hacienda local y sin pago a los funcionarios. Cuando Tomás Herrera trató de justificarse en 1842 ante el Secretario del Tesoro colombiano tras el fallido golpe separatista, declaró que hasta el día anterior del movimiento, el Tesoro Nacional debía a los empleados púbicos de Panamá \$50.074 pesos, lo que habría sido suficiente para justificar la revuelta si consideramos que muchos miembros del gremio mercantil eran funcionarios. (Castillero Calvo, 2004, p. 52)

La separación solo pudo ser frenada con el compromiso por parte del Gobierno de Bogotá de aplicar medidas en pro del mejoramiento comercial. De inmediato, Mariano Ospina Rodríguez, como secretario de Relaciones Exteriores, firmó un pacto de protección de la soberanía panameña con el Gobierno inglés (Martínez Delgado, 1972, p. 72), que permitió que dos líneas de vapor británicas incluyeran a Panamá en sus itinerarios (Castillero Calvo, 2004, p. 57). Tal tratado generó protestas por parte del Gobierno de los Estados Unidos, las cuales fructificarían en el tratado de libre tránsito norteamericano por el Istmo, firmado el 12 de diciembre de 1846 (Martínez Delgado, 1972, p. 72), y que daría pie al inicio de las negociaciones para la construcción del ferrocarril, inaugurando una nueva época de alivio a la deteriorada economía panameña.

En este panorama de deterioro económico y de inestabilidad institucional, la dinámica de ingreso del fisco panameño entre 1831-1845 mostró una sorprendente tendencia al alza, con una pendiente global de 6,047, pero lejos de los promedios anuales de las últimas seis décadas. Este comportamiento fue causado por el mejoramiento de las relaciones comerciales desde 1842, siendo los gravámenes comerciales los más importantes en la determinación del ingreso global, registrándose un coeficiente de correlación de 0,91 entre ambas series, como se evidencia en el gráfico 4.

\section{Gráfico 4.}

Ingresos totales y de impuestos comerciales de la tesorería provincial de Panamá, 1831-1845

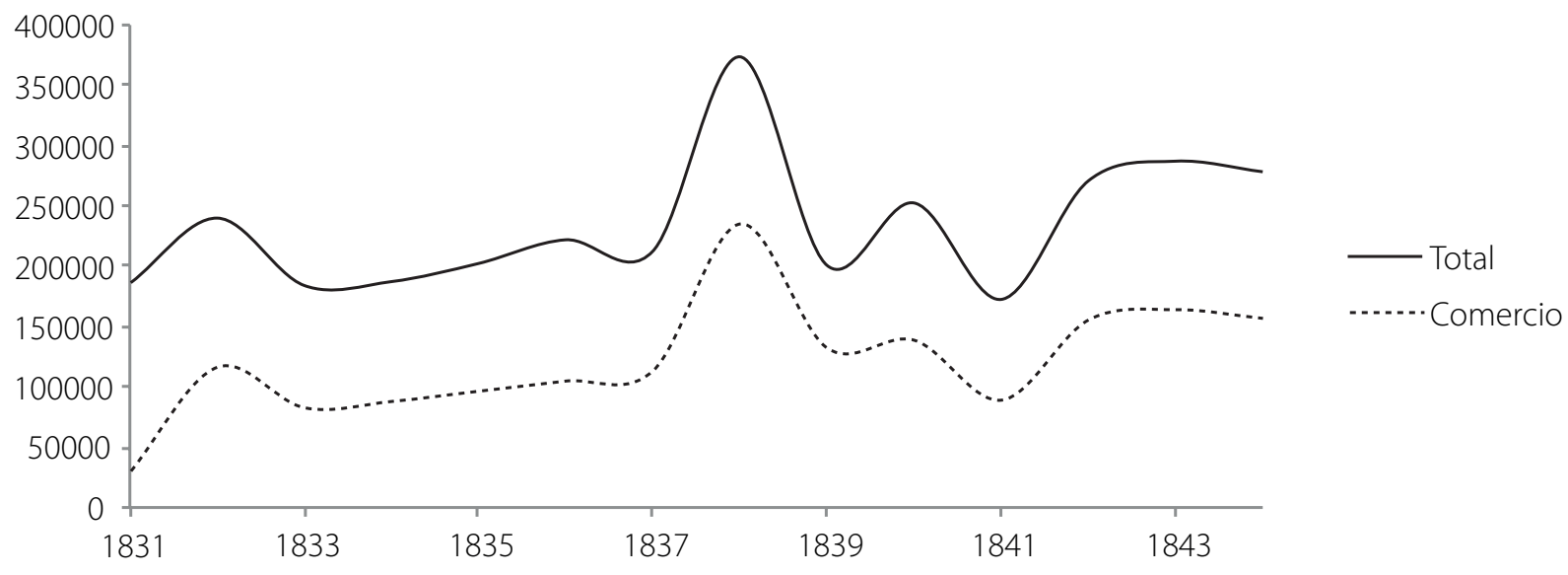

Fuente: elaboración propia con base en

Archivo General de la Nación: Sección: República. Fondo: Tesorerías. Tomos: 6.

Archivo General de la Nación: Sección: República. Fondo: Gobernaciones. Rollos: 299, 300, 301, 302, 303, 304, 305, 306, 307, 308, 309 y 310. 
De esta forma, los impuestos al comercio aportaron el 52,1\% del total, con pendiente de 7,142 , seguido por las remisiones de las cajas provinciales, con el $23,9 \%$, con pendiente de $-1,794$ y con una participación de los estancos del 14,9\%, con pendiente de 751. Los ingresos eventuales aportaron el 6,3\%; los créditos el 1,1\%; los impuestos eclesiásticos, el 1\%, y los impuestos agrícolas, el 0,7\%.

Tabla 7.

Ingresos de la tesorería provincial de Panamá, 1831-1845

\begin{tabular}{|c|r|r|r|r|r|r|r|r|r|r|r|r|r|r|r|}
\hline & $\mathbf{3 1 - 3 2}$ & $\mathbf{3 2 - 3 3}$ & $\mathbf{3 3 - 3 4}$ & $\mathbf{3 4 - 3 5}$ & $\mathbf{3 5 - 3 6}$ & $\mathbf{3 6 - 3 7}$ & $\mathbf{3 7 - 3 8}$ & $\mathbf{3 8 - 3 9}$ & $\mathbf{3 9 - 4 0}$ & $\mathbf{4 0 - 4 1}$ & $\mathbf{4 1 - 4 2}$ & $\mathbf{4 2 - 4 3}$ & $\mathbf{4 3 - 4 4}$ & $\mathbf{4 4 - 4 5}$ \\
\hline Comercio & 30.138 & 116.254 & 82.701 & 87.891 & 96.388 & 104.803 & 113.259 & 235.054 & 132.149 & 138.627 & 88.999 & 155.539 & 163.995 & 156.779 \\
\hline Otras cajas & 45.623 & 76.436 & 59.110 & 58.945 & 69.120 & 78.456 & 58.377 & 93.223 & 25.009 & 50.258 & 22.473 & 38.892 & 48.595 & 56.920 \\
\hline Estancos & 52.806 & 19.644 & 17.418 & 31.590 & 30.718 & 32.961 & 33.639 & 37.334 & 33.718 & 39.237 & 44.686 & 27.281 & 44.479 & 40.466 \\
\hline Varios & 25.533 & 23.460 & 19.259 & 6.253 & 4.409 & 3.256 & 4.125 & 4.325 & 4.624 & 13.393 & 11.963 & 43.433 & 24.424 & 17.523 \\
\hline Crédito & 28.346 & 670 & 0 & 0 & 0 & 0 & 0 & 0 & 0 & 6.000 & 0 & 0 & 0 & 0 \\
\hline Eclesiásticos & 1.016 & 137 & 778 & 1.028 & 1.459 & 1.678 & 2.060 & 2.858 & 4.222 & 3.871 & 1.164 & 4.547 & 4.384 & 4.877 \\
\hline Agricultura & 2.100 & 3.332 & 4.839 & 1.546 & 184 & 785 & 934 & 861 & 1.031 & 1.074 & 3.233 & 1.171 & 1.237 & 1.770 \\
\hline & 185.562 & 239.933 & 184.105 & 187.253 & 202.278 & 221.939 & 212.394 & 373.655 & 200.753 & 252.460 & 172.518 & 270.863 & 287.114 & 278.335 \\
\hline
\end{tabular}

Fuente: elaboración propia con base en

Archivo General de la Nación: Sección: República. Fondo: Tesorerías. Tomos: 6.

Archivo General de la Nación: Sección: República. Fondo: Gobernaciones. Rollos: 299, 300, 301, 302, 303, 304, $305,306,307,308,309$ y 310.

El gasto entre 1833-1845 mostró una pendiente de 7,397, teniendo una significativa transformación en su composición respecto a los 65 años anteriores, pues el gasto militar no fue el rubro más importante. El ramo con mayor participación en el gasto fue el de transferencias a la Tesorería General de la República, con sede en Bogotá, ente encargado de efectuar los gastos nacionales, mismo que comportó el $66 \%$ del total de las erogaciones del Istmo, con una pendiente de 5,372. El siguiente rubro de gasto estuvo constituido por las erogaciones propias del gobierno provincial, con el $21 \%$ del total, con una pendiente de 1,700; por su parte, el gasto militar solo llegó al $13 \%$, con pendiente de 235, debido a la reducción del pie de fuerza en el Istmo y a que la extinción de los movimiento separatistas se efectuó por vías diplomáticas. En tal sentido, es lícito afirmar que mientras la élite pedía mejoras para la reactivación del comercio, el Gobierno de Bogotá era el principal beneficiario de los escasos ingresos que generaba Panamá; así lo demuestran las cifras globales, presentadas en la tabla 8. 
Tabla 8.

Egresos de la tesorería provincial de Panamá, 1833-1845

\begin{tabular}{|r|r|r|r|r|}
\hline & \multicolumn{1}{|c|}{ Administración civil } & \multicolumn{1}{c|}{ Militar } & \multicolumn{1}{c|}{ Transferencias } & \multicolumn{1}{l|}{ Total } \\
\hline $\mathbf{3 3 - 3 4}$ & 43.883 & 22.075 & 118.147 & $\mathbf{1 8 4 . 1 0 5}$ \\
\hline $\mathbf{3 4 - 3 5}$ & 50.339 & 22.409 & 114.505 & $\mathbf{1 8 7 . 2 5 3}$ \\
\hline $\mathbf{3 5 - 3 6}$ & 50.922 & 23.027 & 128.329 & $\mathbf{2 0 2 . 2 7 8}$ \\
\hline $\mathbf{3 6 - 3 7}$ & 51.420 & 25.651 & 144.868 & $\mathbf{2 2 1 . 9 3 9}$ \\
\hline $\mathbf{3 7 - 3 8}$ & 52.736 & 26.580 & 133.078 & $\mathbf{2 1 2 . 3 9 4}$ \\
\hline $\mathbf{3 8 - 3 9}$ & 43.580 & 28.925 & 301.150 & $\mathbf{3 7 3 . 6 5 5}$ \\
\hline $\mathbf{3 9 - 4 0}$ & 52.648 & 29.546 & 118.559 & $\mathbf{2 0 0 . 7 5 3}$ \\
\hline $\mathbf{4 0 - 4 1}$ & 51.240 & 41.523 & 159.697 & $\mathbf{2 5 2 . 4 6 0}$ \\
\hline $\mathbf{4 1 - 4 2}$ & 48.524 & 41.869 & 82.125 & $\mathbf{1 7 2 . 5 1 8}$ \\
\hline $\mathbf{4 2 - 4 3}$ & 50.732 & 35.204 & 184.927 & $\mathbf{2 7 0 . 8 6 3}$ \\
\hline $\mathbf{4 3 - 4 4}$ & 52.548 & 32.485 & 202.081 & $\mathbf{2 8 7 . 1 1 4}$ \\
\hline $\mathbf{4 4 - 4 5}$ & 51.556 & 38.766 & 188.013 & $\mathbf{2 7 8 . 3 3 5}$ \\
\hline Total & $\mathbf{6 0 0 . 1 2 8}$ & $\mathbf{3 6 8 . 0 6 0}$ & $\mathbf{1 . 8 7 5 . 4 7 9}$ & $\mathbf{2 . 8 4 3 . 6 6 7}$ \\
\hline
\end{tabular}

Fuente: elaboración propia con base en Archivo General de la Nación: Sección: República. Fondo: Tesorerías. Tomos: 6. Archivo General de la Nación: Sección: República. Fondo: Gobernaciones. Rollos: 299, 300, 301, 302, 303, 304, $305,306,307,308,309$ y 310.

Así, 1830-1845 se manifiesta como un período de inestabilidad política en el Istmo, debido a los intentos separatistas, que tenían causas apenas lógicas, a saber: el comercio del Istmo se encontraba en parálisis, por lo menos hasta 1842, sin que el Gobierno de la República de la Nueva Granada se mostrase afecto a su liberación, lo cual se manifiesta en la ley de eliminación de derechos de introducción de 1835, condicionada a la construcción de un ferrocarril o un canal, obras para las cuales el Gobierno central no contaba con recursos; contrario a ello, se apropiaba de los sobrantes de la tesorería provincial para sus propios gastos. La independencia de Panamá solo pudo ser pospuesta acudiendo a la protección norteamericana e inglesa, lo cual abriría un nuevo ciclo de bonanza comercial, cuyos productos, de nuevo, no serían gozados por los panameños sino por el Gobierno central.

\section{Conclusiones}

El análisis del fisco panameño revela que durante el período estudiado, el orden institucional y el desempeño económico estuvieron altamente determinados por el movimiento comercial y por las remisiones de fondos de otras tesorerías para el funcionamiento de los cuerpos armados. Así, la reducción de las actividades mercantiles o de la remisión de fondos de otros lugares provocó en la plaza una delicada situación de orden social, en razón a la falta de fondos para los pagos a las Fuerzas Armadas y a los cuerpos administrativos, y además generó la caída de las actividades productivas. 
En este orden de ideas, es fácil comprender las razones por las cuales la élite comercial del Istmo, que encontró su representación en el Cabildo en las épocas de dominio español y en las instituciones de gobierno departamental o provincial durante el período de la República de Colombia y de la Nueva Granada, pugnó por la inminente promulgación del comercio libre. La respuesta de las autoridades metropolitanas y del gobierno republicano con sede en Bogotá fue de carácter transitorio, hundiendo al Istmo en una profunda crisis, por lo menos hasta 1845.

Dicha crisis se manifestó en el deterioro del promedio de ingresos globales del fisco, los cuales registraron una ininterrumpida caída, como lo demuestran las cifras, presentes en el gráfico 5.

\section{Gráfico 5.}

Ingresos fiscales de Panamá, 1780-1845

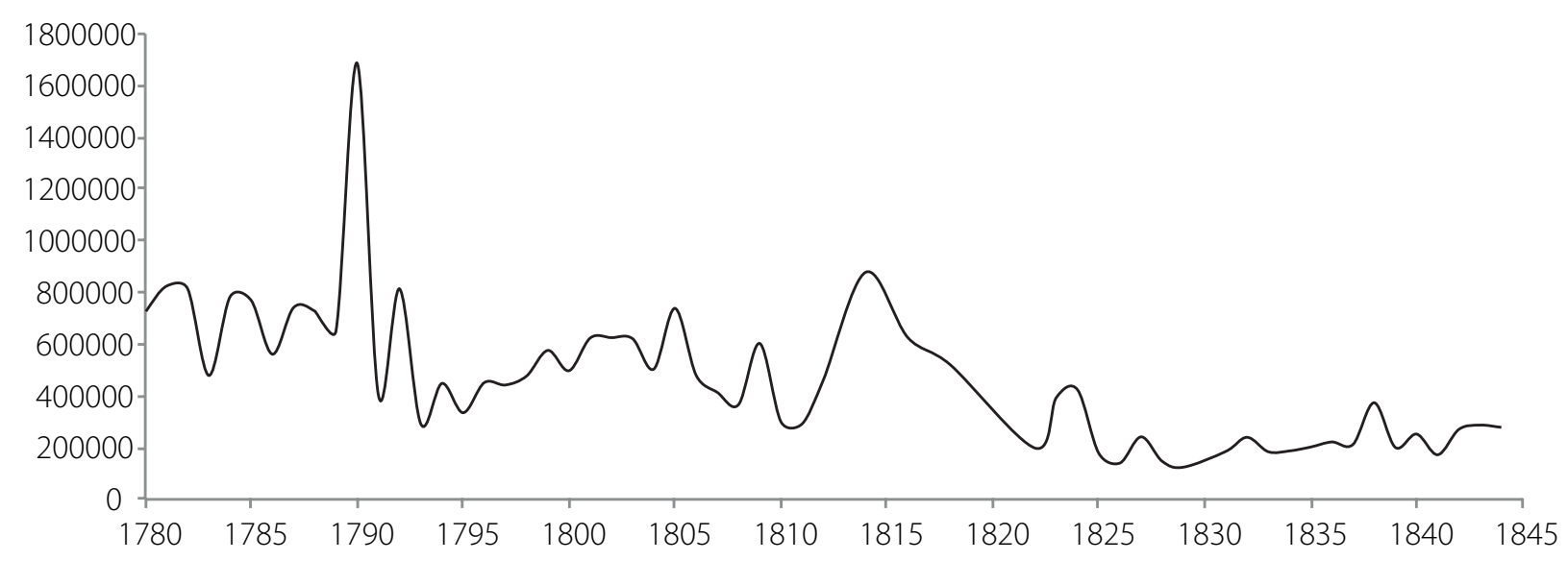

Fuente: elaboración propia con base en

Archivo General de la Nación: Sección: Archivo Anexo II. Fondo: Real Hacienda Cuentas. Caja: 23.

Archivo General de la Nación. Sección: Colonia. Fondo: Real Hacienda. Tomos: 36, 30 y 53.

Archivo General de la Nación: Sección: República. Fondo: Gobernaciones. Rollos: 299, 300, 301, 302, 303, 304, 305, $306,307,308,309$ y 310.

Archivo General de la Nación: Sección: República. Fondo: Ministerio de Hacienda. Tomos: 299, 226 y 299.

Archivo General de la Nación: Sección: República. Fondo: Tesorerías. Tomo: 6.

David M. Rubenstein Rare Book \& Manuscript Library. Duke University. John Jay TePaske Papers, 1500s-1988. Caja: 7.

Entre 1780-1789, el promedio anual de ingreso fue de $\$ 708.253$; entre $1790-1799$ fue de \$592.715; entre 1800-1809 registró \$547.272; en el período de 1810-1818, \$512.657; en 1822$1830, \$ 230.921$, y en $1831-1845, \$ 233.512$. La caída constante del ingreso fiscal es el fiel reflejo del deterioro de las remisiones de situados de Lima, finalizadas durante el período independentista, y la caída del comercio como producto de las guerras metropolitanas y la apertura de las rutas comerciales del Cabo de Hornos y Veracruz, una vez eliminado el dominio español en América. 
La crisis económica y fiscal se tradujo en constante crisis política dentro del Istmo. La independencia de España se pospuso hasta 1821 como producto de la efímera bonanza comercial que significó la autorización del tráfico con colonias extranjeras y neutrales en la década del diez, situación que cambiaría y que obligaría a la élite a declarar la independencia buscando la protección de la recién fundada República de Colombia. Sin embargo, las expectativas fueron mucho más amplias que las concesiones que otorgó el Gobierno colombiano, y rápidamente los panameños buscaron la forma de constituir franquicias comerciales con Inglaterra, debido a la falta de respuesta a sus demandas por parte de Bogotá.

De forma casi inmediata, de nuevo Panamá buscó la tan anhelada libertad comercial promulgando su independencia de Colombia en 1830, intento que fue rápidamente suprimido, pasando a ser parte de la República de la Nueva Granada, de cuyo Gobierno solo obtuvo una autorización condicionada a la construcción de un canal o un ferrocarril para la eliminación de los derechos de importación en 1835, sin ningún apoyo de tipo monetario. Además de ello, los escasos fondos públicos de la provincia, de nuevo fueron a parar a las arcas santafereñas, razón por la cual en 1840, de nuevo se intenta la independencia, sofocada solo por los tratados celebrados con Inglaterra y Estados Unidos, que darían respiro al comercio e inicio a las negociaciones para la construcción del ferrocarril. El costo de ser independiente fue muy alto para la élite comercial panameña, pasando de la fidelidad a España sin resultados, después ser subyugada a los designios santafereños, cuyos gobernantes, por lo menos hasta 1845, se abrogaron el disfrute de los fondos fiscales panameños, aplicando una política de alivio fiscal y comercial titubeante, idéntica a la del dominio español.

\section{Referencias}

\section{Fuentes de archivo}

Archivo General de la Nación: Sección: Archivo Anexo II. Fondo: Real Hacienda Cuentas. Caja: 23.

Archivo General de la Nación. Sección: Colonia. Fondo: Real Hacienda. Tomos: 36, 30 y 53.

Archivo General de la Nación: Sección: República. Fondo: Gobernaciones. Rollos: 299, 300, 301, 302, 303, 304, 305, 306, 307, 308, 309 у 310.

Archivo General de la Nación: Sección: República. Fondo: Ministerio de Hacienda. Tomos: 299, 226 y 299.

Archivo General de la Nación: Sección: República. Fondo: Tesorerías. Tomo: 6.

David M. Rubenstein Rare Book \& Manuscript Library. Duke University. John Jay TePaske Papers, 1500s-1988. Caja: 7.

\section{Libros}

Araúz, C.A. y Pizzurno, P. (1991). El Panamá hispano, 1501-1821. Panamá: Comisión Nacional del V Centenario. Encuentro de Dos Mundos, de España - Diario La Prensa. 
Araúz, C.A. y Pizzurno, P. (1993). El Panamá colombiano, 1821-1903. Panamá: Primer Banco de Ahorros - Diario La Prensa.

Ardant, G. (1975). Financial Policy and Economic Infrastructure of Modern States and Nations. En C. Tilly (ed.), The Formation of Nation State in Western Europe. (pp. 164-242). Nueva Jersey: Princeton University Press.

Ardant, G. (1971). Histoire de l'impôt. París: Fayard.

Bonney, R. (2004). Introduction: The Race of the Fiscal State in Europe, c. 1200-1815. En R. Bonney (ed.). The Race of the Fiscal State in Europe, c. 1200-1815. (pp. 1-18). Nueva York: Oxford University Press.

Bordo, M., Cortes-Conde, R. (eds.). (2006). Transferring Wealth and Power from the Old to the New World: Monetary and Fiscal Institutions in the 17th through the 19th Centuries. Nueva York: Cambridge University Press.

Brewer, J. (1989). The Sinews of Power: War, Money, and the English State, 1688-1783. Nueva York: Alfred A. Knopf.

Castillero Calvo, A. (2004). Historia general de Panamá. Panamá: Comité Nacional del Centenario de la República.

Clamageran, J. (1866). Histoire de l'impôt en France. París: Librairie de Guillaumin.

Comín Comín, F. y Yun-Casalilla, F. (2012). Spain: from Composite Monarchy to Nation State, 1492-1914. En B. Yun-Casalilla, P. O’Brien y F. Comín Comín (eds.), The Rise of Fiscal States. A Global History, 1500-1914 (pp. 233-266). Nueva York: Cambridge University Press.

Dawel, S. (1888). A History of Taxation and Taxes in England from the Earliest Times to Year 1885. Londres: Longmans, Green and Co.

Dickson, P. (1976). The Financial Revolution in England. A Study in Development of Public Credit, 1688-1756. Londres: Macmillan.

Ezpeleta, J. (1989). Relación del gobierno del excelentísimo señor don Josef de Ezpeleta. En G. Colmenares (ed.), Relaciones de mando e informes de los gobernantes de la Nueva Granada. Tomo II (pp. 153-311). Bogotá: Fondo de Promoción de la Cultura del Banco Popular.

Flores Guzmán, R. (2012). Los situados peruanos: desde Chile hasta Panamá, 1700-1800. En C. Marichal y J. Grafenstein (eds.), El secreto del imperio español: los situados coloniales en el siglo XVIII. (pp. 32-59). México: El Colegio de México, Instituto de Investigaciones Dr. José María Mora.

Gil y Lemus, F. (1989). Relación de don Francisco Gil y Lemos. En G. Colmenares (Ed.), Relaciones de mando e informes de los gobernantes de la Nueva Granada. Tomo II (pp. 5-34). Bogotá: Fondo de Promoción de la Cultura del Banco Popular.

Halperin, T. (2005). Guerra y finanzas en los orígenes del Estado argentino, 1791-1850. Buenos Aires: Prometeo Libros.

Jara, A. y TePaske, J. (1990). The Royal Treasuries of the Spanish Empire in America, Vol. 4: Eighteen Century Ecuador. Durham: Duke University Press. 
Jara. A. (1994). El imperio español en América (1700-1820). Santiago de Chile: Editorial Sudamericana.

Jáuregui, L. y Serrano; J. A. (eds.). (1998). Las finanzas públicas en los siglos XVIII y XIX. México: Instituto Mora, 1998.

Kennedy, W. (1913). English Taxation, 1640-1799. An Essay on Policy and Opinion. Londres: G. Bell \& Sons.

Klein, H. (1973). Structure and Profitability of Royal Finance in the Viceroyalty of the Rio de la Plata in 1790. The Hispanic American Historical Review, 53 (3), pp. 440-469.

Klein, H. (1994). Las finanzas americanas del Imperio español: 1680-1809. México: Instituto de Investigaciones Dr. José María Mora.

Marichal, C. (1999). La bancarrota del virreinato, Nueva España y las finanzas del imperio español, 1780-1810. México: Fondo de Cultura Económica.

Marichal, C. y Grafenstein, J. (eds.) (2012). El secreto del imperio español: los situados coloniales en el siglo XVIII. México: El Colegio de México, Instituto de Investigaciones Dr. José María Mora.

Martínez Delgado, L. (1972). Panamá. Su independencia de España, su incorporación a la Gran Colombia, su separación de Colombia y el canal interoceánico. Bogotá: Ediciones Lerner.

Martínez Garnica, A. (1998). El legado de la patria boba. Bucaramanga: Sistemas \& Computadores.

Martínez Garnica, A. (2000). La reasunción de la soberanía por las juntas de notables en el Nuevo Reino de Granada. En M. Chust (ed.), La eclosión juntera en el mundo hispano (pp. 286333). México: Fondo de Cultura Económica - Colegio de México.

Mendinueta, P. (1989). Relación del estado del Nuevo Reino de Granada, presentado por el excelentísimo señor Pedro Mendinueta a su sucesor el excelentísimo señor Don Antonio Amar y Borbón. En G. Colmenares (ed.), Relaciones de mando e informes de los gobernantes de la Nueva Granada. Tomo III (pp. 5-192). Bogotá: Fondo de Promoción de la Cultura del Banco Popular.

Montalvo, F. (1989). Instrucción sobre el estado en que deja el Nuevo Reino de Granada el excelentísimo señor Virrey Don Francisco de Montalvo, en 30 de enero de 1818, a su sucesor, el excelentísimo Señor Don Juan de Sámano. En G. Colmenares (ed.), Relaciones de mando e informes de los gobernantes de la Nueva Granada. Tomo III (pp. 193-350). Bogotá: Fondo de Promoción de la Cultura del Banco Popular.

O'Brien, P. (1967). Government Revenue, 1793-1815: A Study in Fiscal and Financial Policy in the Wars against France. Diss: University of Oxford.

Pebrer, P. (1833). Taxation, Revenue, Expenditure, Power, Statistics, and Debt of the Whole British Empire; Their Origin, Progress, and Present State. With an Estimate of the Capital and Resources of the Empire, and a Practical Plan for Applying Them to the Liquidation of the National Debt. Londres: Baldwing and Cradock. 
Reguart, D. B. (2008). Plan de economía y buena administración o prospecto al gobierno político, militar y económico para el Istmo de Panamá, 30 de diciembre de 1809. En A. Almarza Villalobos y A. Martínez Garnica (eds.), Instrucciones para los diputados del Nuevo Reino de Granada y Venezuela ante la Junta Central Gubernativa de España y las Indias (pp. 167-250). Bucaramanga: Universidad Industrial de Santander.

Sánchez Santiró, E., Jáuregui, L. e Ibarra, A. (eds.). (2001). Finanzas y política en el mundo iberoamericano. Del antiguo régimen a las naciones independientes. México: Universidad Autónoma del Estado de Morelos -Instituto Mora -Facultad de Economía-UNAM.

Stourm, R. (1885). Les finances de la l'ancien régime et de la révolution. Origines du système financier actuel. París: Librairie de Guillaumin.

TePaske, J., Hérnandez J. y Hernandez L. (1976). La Real Hacienda de Nueva España: la Real Caja de México, 1576-1816: México: Instituto Nacional de Antropología e Historia, Departamento de Investigaciones Históricas, Seminario de Historia Económica.

TePaske, J., Klein, H. y Brown, K. (1982a). The Royal Treasuries of the Spanish Empire in America, Vol. 1: Peru. Durham: Duke University Press.

TePaske, J., Klein, H., Brown, K. (1982b). The Royal Treasuries of the Spanish Empire in America, Vol. 2: Upper Peru. Durham: Duke University Press.

TePaske, J., Klein, H. y Brown, K. (1982c). The Royal Treasuries of the Spanish Empire in America, Vol. 3: Chile y el río de la Plata. Durham: Duke University Press.

Vuitry, A. (1866). Etudes sur le régime financier de la France avant la révolution de 1789. París: Librairie de Guillaumin.

Yun-Casalilla, B. (2012). Introduction:The Rise of Fiscal State in Eurasia from a Global, Comparative and Transnational Perspective. En B. Yun Casalilla, P. O'Brien y F. Comín (eds.), The Rise of Fiscal States. A Global History, 1500-1914 (pp. 1-38) Nueva York: Cambridge University Press.

\section{Artículos}

Cucalón, J. (1824). Estado que manifiesta el ingreso y egreso que ha tenido la tesorería departamental de panamá desde el 15 de septiembre de 1823 a 30 de junio de 1824, en que se hizo corte general de caja para continuar la cuenta del segundo año económico según lo dispuesto por el gobierno superior de la República. Gaceta Oficial del Departamento del Istmo. 8 ago.

Cucalón, J. (1825). Estado que manifiesta el ingreso y egreso que ha tenido desde el 1 de enero hasta el 15 de septiembre de 1823 en que se hizo el corte general de caja, para comenzar el año económico según se ha dispuesto por el supremo gobierno en la orden comunicada por esta intendencia el 19 de agosto último. Gaceta Oficial del Departamento del Istmo. 12 oct. 
Dieu, J. P. (2009). La Nueva Planta en su contexto Las reformas del aparato del Estado en el reinado de Felipe V. Hispania, 68, pp. 113-139.

Gaceta del Istmo de Panamá (1826). La contribución directa. 24 ene.: 2.

González Enciso, A. (2008). El Estado Fiscal Militar, una reflexión alternativa. Memoria y civilización: Anuario de Historia de la Universidad de Navarra, 11, pp. 271-295.

Kalmanovitz, S. (2012). El federalismo y la fiscalidad del Estado Soberano de Panamá, 18501886. Revista de Economía Institucional, 14 (27), pp. 99-145.

Meisel, A. (2011). Crecimiento, mestizaje y presión fiscal en el virreinato de la Nueva Granada, 1760-1800. Cuadernos de Historia Económica y Empresarial, 28, pp. 1-97.

Schumpeter, J. A. (2000). La crisis del Estado fiscal. Revista española de control externo, 2(5), pp. 147-192.

Tesorería Departamental del Istmo (1829). Estado de Ingreso y Egreso de la Tesorería Departamental del Istmo desde 1 de julio de 1828 hasta 30 de Junio de 1829. Gaceta de Colombia, 432.

Torres Sánchez, R. (2008). Las prioridades de un monarca ilustrado o las limitaciones del Estado fiscal-militar de Carlos III. Hispania, 68, pp. 407-436.

\section{Tesis}

Pinto Bernal, J. (2011). Finanzas de la República de Colombia, 1819-1830. Bogotá:Tesis de maestría en Historia, Universidad Nacional de Colombia. 